\title{
Intergenerational programming of nephrogenesis and hypertension following feeding of a low-protein diet in rat pregnancy
}

\author{
Matthew Harrison, Simon Langley-Evans and Richard Plant \\ University of Nottingham, Nottingham, UK
}

Epidemiological associations between birth weight and CVD in adult life are supported by rodent experiments showing that undernutrition in fetal life programmes adult blood pressure ${ }^{(1)}$. In rats the feeding of a maternal low-protein (LP) diet during gestation programmes hypertension ${ }^{(2)}$. Given current interest in the role of epigenetic modification of gene expression, the present study assesses the potential for a nutritional insult to impact across several generations.

Pregnant female Wistar (F0) rats were fed a control (Con; $n$ 10) or low-protein (LP) diet ( $n$ 10) throughout gestation. At delivery all animals were fed the same standard laboratory chow diet. At approximately 10 weeks of age F1-generation offspring were mated to produce a second generation (F2) without any further dietary change. The same procedure was followed to produce the F3 generation. Blood pressure was determined at 8 weeks of age and nephron number was determined at 10 weeks of age ${ }^{(3)}$. Data were analysed using a mixed model ANOVA, with gender and maternal diet as main factors, with adjustment for litter of origin. F1- and F2-generation LPexposed offspring exhibited raised systolic blood pressure (SBP) compared with Con rats $(P<0.001$; Table). This intergenerational transmission in the F2 generation occurred via both the maternal and paternal lines. Reduced total nephron number per kidney was observed in F1 $(P<0.001)$ and F2 $(P<0.05)$ animals either subjected to protein restriction during gestation or derived from breeding crosses in which the parents were originally subjected to protein restriction during fetal life.

\begin{tabular}{|c|c|c|c|c|c|c|c|c|c|c|c|}
\hline \multirow[b]{3}{*}{ Generation } & \multirow[b]{3}{*}{ Maternal diet and cross $\dagger$} & \multicolumn{6}{|c|}{ Males } & \multicolumn{4}{|c|}{ Females } \\
\hline & & \multirow[b]{2}{*}{$n$} & \multicolumn{2}{|c|}{$\mathrm{SBP}(\mathrm{mmHg})$} & \multicolumn{2}{|c|}{ Nephrons per kidney } & \multirow[b]{2}{*}{$n$} & \multicolumn{2}{|c|}{ SBP $(\mathrm{mmHg})$} & \multicolumn{2}{|c|}{ Nephrons per kidney } \\
\hline & & & Mean & SE & Mean & SE & & Mean & $\mathrm{SE}$ & Mean & $\mathrm{SE}$ \\
\hline \multirow[t]{2}{*}{$\overline{F 1}$} & Con & 31 & 131 & 3 & 19053 & 1643 & 29 & 135 & 4 & 21430 & 970 \\
\hline & LP & 28 & $139 *$ & 5 & $12752 *$ & 2158 & 29 & $137 *$ & 4 & $13936^{*}$ & 1081 \\
\hline \multirow[t]{4}{*}{ F2 } & Con $\times$ Con & 33 & 121 & 3 & 21187 & 912 & 33 & 126 & 2 & 19367 & 883 \\
\hline & Con $\times$ LP & 24 & $136^{*}$ & 3 & $13396^{*}$ & 939 & 24 & $131 *$ & 5 & $11740 *$ & 1811 \\
\hline & $\mathrm{LP} \times \mathrm{Con}$ & 23 & $133^{*}$ & 4 & $12407 *$ & 1176 & 26 & $135^{*}$ & 4 & $13329 *$ & 1825 \\
\hline & $\mathrm{LP} \times \mathrm{LP}$ & 35 & $129^{*}$ & 3 & $11327^{*}$ & 768 & 29 & $130 *$ & 3 & $13356^{*}$ & 1237 \\
\hline \multirow[t]{2}{*}{ F3 } & Con $\times$ Con & 31 & 144 & 3 & 11503 & 1344 & 29 & 148 & 3 & 13805 & 1214 \\
\hline & $\mathrm{LP} \times \mathrm{LP}$ & 23 & 146 & 3 & 11530 & 915 & 24 & 143 & 3 & 10954 & 1263 \\
\hline
\end{tabular}

Mean values were significantly different from those of Con rats of same gender and generation: $* P<0.05$. $†$ For F2 and F3 crosses the dietary origin of the male parent is shown before the female parent.

The data are consistent with previous findings relating to the effects of an LP diet on blood pressure and renal development in the F1 generation $^{(4)}$. For the first time, it has been shown that fetal protein restriction may play a critical role in determining blood pressure and overall disease risk in a subsequent generation. It is clear from the data that both males and females can transmit their phenotype to a subsequent generation. This finding suggests that maternal diet can influence the nature of epigenetic markers in germ line cells.

1. Langley-Evans SC, Welham SJ, Sherman RC \& Jackson AA (1996) Clin Sci 91, 607-615.

2. Langley-Evans SC, Phillips GJ \& Jackson AA (1994) Clin Nutr 13, 319-324.

3. Welham SJ, Wade A \& Woolf AS (2002) Kidney Int 61, 1231-1242.

4. Langley-Evans SC, Welham SJ \& Jackson AA (1999) Life Sci 64, 965-974. 